\title{
Use of morphology in spelling by children with dyslexia and typically developing children
}

\author{
DERRICK C. BOURASSA \\ University of Winnipeg, Winnipeg, Manitoba, Canada \\ and \\ REBECCA TREIMAN and BRETT KESSLER \\ Washington University, St. Louis, Missouri
}

\begin{abstract}
In English and some other languages, spelling problems that arise at a phonological level can sometimes be solved through consideration of morphology. For example, children could infer that tuned should contain an $n$ and that fighting should contain a $t$ because their stems include these letters. Children could thus avoid misspellings that might otherwise occur, such as "tud" and "fiding." We used a spelling-level match design to examine the extent to which children with dyslexia and younger typical children use morphology in this way. Both groups of children benefited from morphology to some extent, but not as much as they could have given their knowledge of the stems. Our results suggest that the spellings produced by older children with dyslexia are similar to those of younger normal children in their morphological characteristics, as well as in other ways.
\end{abstract}

In an alphabetic writing system, the spelling of a word reflects the sounds that it contains. Learning to spell, in large part, involves learning the mappings between sounds and letters. Difficulties of several sorts may arise as children learn and use these mappings. One source of difficulty is phonemic segmentation skills that are not fully developed. Other difficulties occur because of irregularities in the sound-to-spelling correspondences of a writing system. In English and certain other languages, spelling difficulties at the phonological level can sometimes be overcome through the use of morphological information. In the present study, we examined the extent to which typical learners and learners with dyslexia use morphology to solve phonological spelling problems.

Children learn most efficiently and productively if they can divide spoken words into units of the size represented by the writing system - phonemes in the case of English and other alphabetic systems. However, the ability to segment spoken words into phonemes develops later than the ability to segment words into such units as syllables,

This research was supported by Grant 12-FY00-51 from the March of Dimes Birth Defects Foundation, Grant BCS-0130763 from the National Science Foundation, and Grant 227563 from the Natural Sciences and Engineering Research Council of Canada. We thank Laura Kaakati and Rochelle Evans for research assistance and the schools and children for their cooperation. Also, thanks to Joanne Carlisle and two anonymous reviewers for their comments. Correspondence concerning this article should be addressed to D. C. Bourassa, Department of Psychology, University of Winnipeg, 515 Portage Ave., Winnipeg, MB, R3B 2E9 Canada (e-mail: d.bourassa@uwinnipeg.ca).

Note-This article was accepted by the previous editorial team, when Colin M. MacLeod was Editor. onsets (initial consonants or clusters), and rimes (vowel + final consonant units) (see, e.g., Liberman, Shankweiler, Fischer, \& Carter, 1974; Treiman \& Zukowski, 1991). Consider a young child who conceptualizes the onset of a word like fly as a single unit. If this child has not separately learned a spelling for the /fl/ unit, the child may misspell the word as "fi" or "fy" (e.g., Caravolas \& Bruck, 1993; Treiman, 1991). ${ }^{1}$ Such spelling errors do not reflect any irregularity in the spelling of the onset cluster. Instead, the errors reflect the child's difficulty in analyzing speech at the level of phonemes.

Links between phonemes and graphemes that are irregular or unpredictable also cause difficulty for learners. For example, the phoneme /æ/ is spelled as $a$ in such English words as bat and flag but as ai in plaid. Situations such as this are common in English, more common than in such languages as Finnish or Italian. In some cases of one-tomany links from sounds to letters, spellers could choose the correct letter if they considered the sound's position in the word or syllable or the identity of the surrounding sounds (Kessler \& Treiman, 2001). In other cases, such disambiguation is not possible. This is true for the /æ/ of plaid, and it is also true for the flaps that occur in certain dialects of English, including North American English. The second consonants of such words as water, writer, and rider are almost always pronounced as flaps. Flaps are made with a quick tap of the tongue against the ridge that lies behind the upper teeth, and the flap that occurs in writer sounds no different from the one that occurs in rider. Indeed, these two words are homophonous for most Americans, including the population we studied in the present research. It is not possible to predict on the basis of a flap's sound whether it should be spelled as $t$ or $d$. Chil- 
dren do not always make the same decisions that the writing system does, leading to misspellings such as "woodr" for water (e.g., Ehri \& Wilce, 1986; Read, 1975).

In learning to spell, children must overcome both segmentation problems and irregularity problems. How do children manage to do this? Some of the problems could be solved if children considered a word's morphological structure. A case in point is the segmentation problem that arises for words that end with consonant clusters, such as brand. If children's phonological segmentation skills are insufficient to allow them to conceptualize a separate $/ \mathrm{n} /$ in the spoken form of brand, they might produce misspellings such as "brad" (e.g., Treiman, Zukowski, \& Richmond-Welty, 1995). However, such children may be able to include an $n$ when spelling a two-morpheme word such as tuned if they relate this word to its stem, tune. Indeed, Treiman and Cassar (1996) found that young children were significantly more likely to symbolize the first segment of a final consonant cluster with an appropriate letter when a stem existed that could aid their spelling, as with tuned, than when no such stem existed, as with brand.

Morphology could potentially help children deal with certain irregularities as well. Consider a young child who is unsure how to spell the flaps of daughter and body. Such a child should produce more accurate spellings for the flaps of waiting and cloudy if he or she relates these words to their stems, wait and cloud. Indeed, Treiman, Cassar, and Zukowski (1994) found that the proportion of correct spellings of flaps was higher for two-morpheme words, such as waiting and cloudy, than for one-morpheme words, such as daughter and body. This was true as early as kindergarten and first grade. These results suggest that children use their knowledge of related words, to some extent, to help deal with irregularities in the mappings from sounds to letters.

The findings that we have just described with Englishspeaking children, together with findings from learners of such languages as French (e.g., Pacton, Fayol, \& Perruchet, 2002; Sénéchal, 2000) and Greek (e.g., Chliounaki \& Bryant, 2002), suggest that normally developing children make some use of morphology from fairly early on in the development of spelling. However, we should not overstate the extent of this benefit. Even for morphologically transparent English words, such as waiting, children do not benefit from their knowledge of the stem as much as they could when spelling the inflected word. For example, a child who consistently uses $t$ to spell the final segment of wait may use $t$ less often to spell the medial segment of waiting. Moreover, many words that contain more than one morpheme are more opaque than are words such as waiting. A child may not know that magician is related to magic, for example, and so may not spell the two words in a similar manner (e.g., Sterling, 1983). Children's knowledge about the morphological relationships among the words in their spoken vocabularies increases as they develop (e.g., Carlisle \& Fleming, 2003), and with it their ability to use these relationships for the benefit of spelling. This is a lengthy process, and even adult spellers may not take full advantage of morphology (e.g., Fischer, Shankweiler, \& Liberman, 1985).

So far, we have seen that children who are learning to read and write at a typical pace make some use of morphology to help overcome segmentation problems and irregularity problems. What about children who experience severe difficulties in the acquisition of literacy, even while performing well in other academic subjects? Such children are often labeled dyslexic or reading disabled. These children typically have problems with spelling, as well as with reading, and their difficulties with spelling are often more severe and persistent than their difficulties with reading. Although much of the research on children with dyslexia has examined reading, the spelling skills of these children have been the focus of an increasing number of studies.

Children with dyslexia, research suggests, are poor at segmenting spoken words into smaller units (e.g., Goswami, 2003). Their spelling reflects their poor phonological awareness. For example, children with dyslexia may fail to spell the interior consonants of cluster onsets, omitting the /1/ of fly but successfully spelling this same consonant when it does not appear in a cluster (e.g., Bruck \& Treiman, 1990; Kibel \& Miles, 1994). Children with dyslexia also have difficulty in choosing the correct spellings for sounds that have one-to-many mappings. For example, Bourassa and Treiman (2003) observed that children with dyslexia sometimes spelled the flaps of such words as potato and tomato with $d$, rather than with $t$.

If children with dyslexia and typically developing children encounter the same kinds of problems in learning to spell, what allows the typical children to overcome these problems and progress more rapidly? One possibility is that typically developing children use morphological information to help solve certain problems that occur at a phonological level, but that children with dyslexia are less able to do this. To test this hypothesis, one may compare older children who have dyslexia and younger typical children who perform at a similar level on a standardized spelling test. In this spelling-level match design, the younger children serve as a control group, in that their performance represents typical skills for the selected spelling level. If the children with dyslexia perform more poorly on morphological skills than does the control group, this would suggest that the children with dyslexia have a particular problem with these skills that could help explain their slow progress.

Carlisle (1987) used a spelling-level match design in a study of ninth graders who had been identified as having specific disabilities in reading and writing. The ninth graders performed very similarly to a group of typical fourth graders on a standardized spelling test. Differences between the groups emerged in the tendency to spell derived words as wholes. The ninth graders were more likely than the fourth graders to spell a stem correctly while spelling a derived form incorrectly (e.g., "equal" for equal and "eqalty" for equality). They were also more likely to spell the derived form correctly and the stem incorrectly 
(e.g., "equl" for equal and "equality" for equality). Carlisle interpreted these results as suggesting that the older children with dyslexia did not use morphology effectively in spelling complex words. In another study, Hauerwas and Walker (2003) compared middle-school children who had reading and spelling deficits with normally achieving children in the second and third grades. The older children with spelling problems were less likely to spell a stem consistently in inflected and base words. For example, they did not necessarily spell call the same way when it appeared in called and when it appeared without an inflectional suffix. This finding, like Carlisle's, appears to support the notion that children with dyslexia have particular difficulty representing morphological information in their spellings - this time, for the case of inflected words. However, the groups studied by Hauerwas and Walker do not seem to have been well matched for spelling ability. The older and younger children performed similarly on one standardized spelling test, but the older children performed substantially more poorly on a spelling test involving the base words. Further complicating the picture, Elbro and Arnbak (1996) reported that Danish children with dyslexia took advantage of morphological structure in reading and that the benefits of morphology were actually larger for the children with dyslexia than for typical younger learners.

Because the past research does not provide a clear answer to the question of how children with dyslexia compare with younger normal children in their use of morphology, we revisited this issue in the two experiments reported here. In Experiment 1, we used a spelling-level match design to ask whether and to what extent older children with dyslexia and normally progressing younger children use morphology to help solve spelling problems that arise from imperfect segmentation skills. Specifically, we examined the extent to which children benefit from the stems of two-morpheme words when spelling word-final consonant clusters. For example, can children use the fact that tuned contains the stem tune as a clue that tuned should be spelled with an $n$ ? If so, children should be less likely to omit the $n$ of a two-morpheme word such as tuned than the $n$ of a one-morpheme word such as brand. The results of Treiman and Cassar (1996), described earlier, suggest that typically developing young children derive some benefit from morphology in such cases. In Experiment 1, we asked whether older dyslexic children also do this.

\section{EXPERIMENT 1}

\section{Method}

\section{Participants}

Children with dyslexia. The children were recruited through three institutions: Michigan Dyslexia Institute, William Beaumont Hospital Center for Human Development, and Eton Academy. The first two organizations provide evaluation and tutoring for dyslexic children and adults. Eton Academy is a private day school for children with dyslexia and other learning difficulties. All three institutions are located in the suburbs of Detroit, Michigan.

Administrators at each institution nominated possible participants who had been classified as developmentally dyslexic. Parental permission to participate was granted for 37 children, all of whom were native speakers of English. To be included in the final sample, a child had to meet three criteria: (1) Full Scale Standard IQ of at least 85 (Wechsler, 1991); (2) performance below the 25th percentile for the child's age group on both the spelling and the reading subtests of the third edition of the Wide Range Achievement Test (WRAT3; Wilkinson, 1993), based on the combined performance across the two forms of each subtest; ${ }^{2}$ and (3) performance below the fourthgrade level on the spelling subtest of the WRAT3, based on the combined performance across the two forms. These selection procedures are similar to those in many previous studies (e.g., Bruck, 1988; Bruck \& Treiman, 1990; Pennington et al., 1986). We selected children who scored below the fourth-grade level on the standardized spelling test because the influences on spelling of interest here tend to be largest among children with spelling levels ranging from first to third grade (e.g., Treiman \& Cassar, 1996; Treiman et al., 1994).

Twenty-five of the potential dyslexic participants (19 of them male) met our criteria and took part in the study. These children ranged in age from 9 years, 2 months to 14 years, 7 months, with a mean age of 11 years, 5 months. Table 1 shows the dyslexics' mean grade level and percentile scores on the spelling and reading subtests of WRAT3. The mean Full Scale IQ for this sample was 100.20 $(S D=8.59$; range, $85-123)$. The grade placements of the children with dyslexia ranged from third grade to ninth grade, with most of these children in the fifth, sixth, or seventh grade.

Typically developing children. Parental permission to participate was granted for 59 first- to third-grade children who attended one of four schools in suburban Detroit. All were native speakers of English. To be included, a child had to meet two criteria: (1) performance at or above the 25 th percentile for the age group on both the spelling and the reading subtests of the WRAT3, based on the combined performance across the two forms of each subtest, and (2) performance below the fourth-grade level on the spelling subtest of the WRAT3, based on the combined performance across the two forms. Thirty-nine of the children met these criteria. These children

Table 1

Mean Scores on Spelling and Reading Subtests of WRAT3 for Children with Dyslexia and Spelling-Level-Matched Typical Children, With Standard Deviations and Ranges

\begin{tabular}{|c|c|c|c|c|c|c|}
\hline \multirow[b]{3}{*}{ Measure } & \multicolumn{6}{|c|}{ Group } \\
\hline & \multicolumn{3}{|c|}{$\begin{array}{c}\text { Children With } \\
\text { Dyslexia }\end{array}$} & \multicolumn{3}{|c|}{ Typical Children } \\
\hline & $M$ & $S D$ & Range & $M$ & $S D$ & Range \\
\hline Spelling grade equivalent & 2.6 & 0.8 & $1.7-3.9$ & 2.6 & 0.8 & $1.0-3.9$ \\
\hline Spelling percentile & 7.1 & 4.0 & $1.0-14.0$ & 57.2 & 15.6 & $27.0-84.0$ \\
\hline Reading grade equivalent & 3.3 & 0.8 & $1.9-5.5$ & 3.1 & 0.8 & $1.2-4.3$ \\
\hline Reading percentile & 9.8 & 5.5 & $1.0-23.0$ & 65.0 & 19.4 & $30.0-93.0$ \\
\hline
\end{tabular}


had a mean spelling grade level of $2.8(S D=0.8$; range, 1.0-3.9) on the spelling subtest of the WRAT3. To equate the dyslexic and control groups on sample size $(n=25)$, the data from 14 control children were randomly removed from further analyses. The final sample of 25 control children ( 12 of them male) ranged in age from 6 years, 6 months to 8 years, 10 months, with a mean age of 7 years, 8 months. Table 1 shows the mean grade level and percentile scores on the spelling and reading subtests of WRAT3 for the children in the control group. The children with dyslexia were very similar to the control children in terms of mean spelling- and reading-gradelevel performance, with no significant group differences on these measures ( $p \mathrm{~s}>.30$ according to $t$ tests). ${ }^{3}$

\section{Stimuli}

The experimental stimuli appear in Appendix A. Drawn from Treiman and Cassar (1996), they included 30 words with two-consonant final clusters and 15 words with single final consonants. Among the words with final consonant clusters were 15 in which the second consonant of the final cluster was an inflectional ending. These words, such as bars, tuned, and raced, are called the morphologically complex items. In the other 15 words with final consonant clusters, the second consonant of the cluster was not a separate morpheme. These words, which included Mars, brand, and boast, are called the morphologically simple items. (In some of these items, such as collect, the final consonant is etymologically a separate element, but we do not classify it as a separate morpheme because it is extremely unlikely that children, or indeed most adults, consider it as such.) The morphologically simple and complex words were matched with respect to the phonemes in their final clusters and for word length in number of letters. In most cases, the conventional spellings of the last two phonemes were not the same in the two types of final cluster items, which is inevitable given the spelling conventions of English. The 15 words with single final consonants were the stems (e.g., bar, tune, race) of the 15 morphologically complex words with final consonant clusters. The morphologically simple and complex items did not differ significantly on two different measures of word frequency (Carroll, Davies, \& Richman, 1971; Zeno, Ivenz, Millard, $\&$ Duvvuri, 1995). The stems were significantly more frequent than the words with final clusters.

For purposes of presentation, the 30 final cluster words were randomly intermixed to form List 1 . List 2 comprised the 15 stems, which were arranged in a random order.

\section{Procedure}

The children were tested individually. The child was told that he or she would be asked to spell some words. The experimenter said each word, used it in a sentence, and then said the word again. The child was asked to repeat the target word. The child was given three chances to do so, and all the children successfully repeated all the target words. The child then wrote the word. The experimenter provided general encouragement but did not indicate whether specific spellings were correct or incorrect. If the experimenter could not make out a letter the child had written, he or she inquired about the intended letter after the child had finished spelling the word. Each child spelled the words in List 1 , followed by those in List 2 . There was a 15-min break between the two lists, during which time the child worked on age-appropriate mathematics problems.

\section{Scoring}

Our primary interest was in how children spelled the words' final consonants. The spellings were scored for whether these consonants were represented in a phonologically plausible manner, regardless of whether conventional letters were used. Appendix A lists the letters that were designated as plausible spellings of the final consonants in each final cluster word. For comparability, the same spellings were accepted for the morphologically simple and complex final cluster words in a pair. A child's spelling of a final consonant word was scored as an A response if it consisted of a phonologically plausible representation of the first consonant, but not of the second consonant, of the final cluster, followed optionally by $e$. Examples of A spellings from the present experiment are "drif" for drift, "bline" for blind, and "ern" for earned. B responses consisted of a phonologically plausible representation of the second, but not the first, consonant of the final cluster, followed optionally by $e$. Examples include "alet" for elect and "kite" or "cid" for kicked. We classified a spelling as an $\mathrm{AB}$ response if it included phonologically plausible representations of both consonants of the final cluster, in the correct order. An $e$ could intervene between the first and the second consonants; final $e$ was also accepted. Sample AB spellings include "fest" for feast, "boste" for boast, and "lind" for leaned. Here and elsewhere, reversals of individual letters were counted as correct, so that "creqes" for creeps was scored as an AB spelling. Such reversals were quite uncommon. Spellings that did not fit into any of the preceding categories were scored as Other. Included in this last category were a few cases in which the phonemes of final consonant cluster were spelled in the wrong order, as in "lodn" for loaned.

For the stems, which ended with single consonants, a spelling was scored as A if it ended with a phonologically plausible representation of the word's final consonant, followed optionally by $e$. Examples are "rack" for rake and "rase" for race. Appendix A shows the final consonant spellings that were accepted for each stem. For comparability, these were the same spellings that were accepted as A responses to the final cluster words. Spellings of stems that did not fit into the A category were scored as Other.

\section{Results}

Table 2 shows the mean proportion of responses in each category for the various types of stimuli for the children with dyslexia and the comparison children. Separate analyses were carried out for each type of response. ${ }^{4}$

Two analyses were conducted for A responses. The first analysis compared children with and without dyslexia on the proportion of A responses to the stems. A $t$ test revealed no reliable difference between the groups. The second analysis examined A responses to words with final consonant clusters. An ANOVA with the factors of group (dyslexic vs. nondyslexic) and morphology (simple vs. complex) revealed no significant effects.

For words with final consonant clusters, we are particularly interested in B responses, or spellings in which the first consonant of the final consonant cluster is omitted. As Table 2 shows, such omissions were more common for simple words, such as brand, than for complex words, such as tuned. Importantly, this held true for both children with dyslexia and typically developing children. These impressions were confirmed by an ANOVA with group and morphology as factors, which revealed only a main effect of morphology $\left[F_{1}(1,48)=26.91, p<.001 ; F_{2}(1,14)=3.15\right.$, $p=.097]$. Neither the main effect of group nor the group $\times$ morphology interaction approached significance.

$\mathrm{AB}$ spellings reveal the ability of the participants to represent both consonants of a final cluster in a phonologically appropriate manner. An ANOVA with group and morphology as factors revealed only a main effect of morphology $\left[F_{1}(1,48)=23.45, p<.001 ; F_{2}(1,14)=\right.$ $2.66, p=.125]$. Neither the main effect of group nor the group $\times$ morphology interaction was reliable. These results show that both the children with dyslexia and the typically developing children were more likely to symbolize the two consonants of a final consonant cluster when 
Table 2

Mean Proportions of Spellings of Various Types in Experiment 1, With Standard Deviations

\begin{tabular}{|c|c|c|c|c|c|c|c|c|c|}
\hline \multirow[b]{3}{*}{ Group } & \multirow[b]{3}{*}{ Stimulus Type } & \multicolumn{8}{|c|}{ Type of Spelling } \\
\hline & & \multicolumn{2}{|c|}{$\mathrm{A}$} & \multicolumn{2}{|c|}{$\mathrm{B}$} & \multicolumn{2}{|c|}{$\mathrm{AB}$} & \multicolumn{2}{|c|}{ Other } \\
\hline & & $\bar{M}$ & $\overline{S D}$ & $M$ & $S D$ & $M$ & $\overline{S D}$ & $M$ & $S D$ \\
\hline \multirow[t]{3}{*}{ Children with dyslexia } & $\begin{array}{l}\text { Final cluster, } \\
\text { morphologically } \\
\text { simple }\end{array}$ & .02 & .05 & .12 & .14 & .82 & .17 & .05 & .08 \\
\hline & $\begin{array}{l}\text { Final cluster, } \\
\text { morphologically } \\
\text { complex }\end{array}$ & .02 & .04 & .05 & .10 & .88 & .15 & .05 & .06 \\
\hline & $\begin{array}{l}\text { No final cluster, } \\
\text { stem }\end{array}$ & .98 & .04 & & & & & .02 & .04 \\
\hline \multirow[t]{3}{*}{ Typical children } & $\begin{array}{l}\text { Final cluster, } \\
\text { morphologically } \\
\text { simple }\end{array}$ & .02 & .04 & .14 & .16 & .77 & .19 & .06 & .10 \\
\hline & $\begin{array}{l}\text { Final cluster, } \\
\text { morphologically } \\
\text { complex }\end{array}$ & .02 & .05 & .08 & .12 & .85 & .20 & .05 & .12 \\
\hline & $\begin{array}{l}\text { No final cluster, } \\
\text { stem }\end{array}$ & .97 & .05 & & & & & .03 & .05 \\
\hline
\end{tabular}

Note-See the text for an explanation of the types of spellings.

these consonants appeared in a morphologically complex word (e.g., tuned) than when they appeared in a simple word (e.g., brand). This pattern of better performance on complex words than on simple words is the same pattern as that found in the analysis of B responses.

Additional analyses were performed to examine Other responses. We first compared dyslexic and control children on the proportion of Other responses to stems. A $t$ test revealed no reliable difference between the groups. A 2 (group) $\times 2$ (morphology) ANOVA on Other responses to words with final consonant clusters also showed no significant effects.

If the children used their knowledge of the stem to the maximum extent possible when they spelled the morphologically complex words with final clusters, they should have produced as many spellings containing $n$ when spelling a word such as rained as when spelling a word such as rain. We examined the proportion of spellings containing an appropriate representation of the critical phoneme$/ \mathrm{n} /$, in this example - for the morphologically complex words and the stems. For the morphologically complex words, the proportion of spellings in which the first phoneme of the cluster was represented was .91 for the children with dyslexia and .88 for the typical children. (These proportions are the sum of the A spellings, the AB spellings, and the few Other spellings that involved a reversal.) For stems, the proportion of spellings that represented the critical phoneme was .98 for the dyslexic children and .97 for the control children. An ANOVA with the factors of group (dyslexic vs. nondyslexic) and word type (morphologically complex words vs. stems) yielded a main effect of word type $\left[F_{1}(1,48)=17.42, p<.001 ; F_{2}(1,28)=\right.$ $22.35, p<.001]$ but no other significant effects. Thus, neither the children with dyslexia nor the typical younger children used morphological knowledge as much as they could have when spelling the complex words. This was true to the same extent for both groups of children.

Additional analyses were carried out to examine the children's spellings of the entire stems when they occurred alone and when they occurred in a two-morpheme inflected word. For example, a child who spelled lace as "lase" and laced as "lased" has maintained the spelling of the stem, whereas a child who spelled lace as "lase" and lased as "laced" did not spell the stem the same way. (The presence or absence of a final $e$ was disregarded in this scoring, since this letter is dropped in conventional English when a vowel-initial ending is added. Doubling of a final consonant would also have been disregarded, although it did not occur in the present experiment.) The proportion of cases in which the spelling of the stem was maintained in the morphologically complex words was .54 for the children with dyslexia and .65 for the typical children. The trend for a higher rate of stem preservation by the typically developing children was not statistically significant $(p>.05)$. The relatively low rates of stem preservation for both groups provide additional support for the idea that neither the typically developing children nor the children with dyslexia made full use of the stems when spelling the morphologically complex words.

Although our main focus was on the phonological appropriateness of the final consonants in the children's spellings, we also examined the overall correctness of the spellings (see Table 3). Two analyses were conducted. The first analysis examined the proportions of correct responses to words with final consonant clusters. An ANOVA with group (dyslexic vs. nondyslexic) and morphology (simple vs. complex) as factors revealed only a group $\times$ morphology interaction $\left[F_{1}(1,48)=8.25, p<.01 ; F_{2}(1,14)=\right.$ $13.44, p<.01]$. Follow-up analyses revealed that controls performed better than dyslexics on morphologically 


\begin{tabular}{|c|c|c|c|c|c|c|}
\hline \multicolumn{7}{|c|}{$\begin{array}{c}\text { Table } 3 \\
\begin{array}{c}\text { Mean Proportions of Fully Correct Spellings of Each Word Type } \\
\text { in Experiment 1, With Standard Deviations }\end{array}\end{array}$} \\
\hline \multirow[b]{2}{*}{ Group } & \multicolumn{2}{|c|}{$\begin{array}{l}\text { Morphologically } \\
\text { Simple }\end{array}$} & \multicolumn{2}{|c|}{$\begin{array}{c}\text { Morphologically } \\
\text { Complex }\end{array}$} & \multicolumn{2}{|c|}{ Stem } \\
\hline & $M$ & $S D$ & $M$ & $S D$ & $M$ & $S D$ \\
\hline Children with dyslexia & .28 & .16 & .25 & .22 & .42 & .27 \\
\hline Typical children & .26 & .19 & .39 & .24 & .50 & .25 \\
\hline
\end{tabular}

complex items $\left[t_{1}(48)=2.17, p<.05 ; t_{2}(14)=4.43, p<\right.$ $.01]$, but not on morphologically simple items $(p s>.40)$. Thus, although dyslexic and control children were equally able to represent both final consonants in morphologically complex words (see the analysis of AB responses above), the controls produced more fully correct spellings of these words. The second analysis compared children with and without dyslexia on the proportion of correct responses to the stems. A $t$ test revealed no reliable difference between the groups.

\section{Discussion}

Young children who are learning to spell in English often have difficulty with consonant clusters. For two-phoneme clusters at the ends of words, a common error is to omit the first consonant of the cluster and represent the second, as in "blid" for blind (e.g., Read, 1975; Treiman et al., 1995). This error appears to reflect a difficulty in segmenting the rime of blind into the vowel + consonant + consonant sequence assumed by the writing system. The present results confirm that typically developing children make spelling errors on word-final consonant clusters during the first few years of elementary school. A more novel finding is that children with dyslexia produce these same errors even in late elementary school and middle school. When they attempted single-morpheme words such as blind, the older children with dyslexia symbolized only the last consonant of the final cluster $12 \%$ of the time. This rate was six times higher than the rate at which they spelled only the first consonant of the final cluster.

An inflected word such as leaned ends with the same /nd/ sequence as does the one-morpheme word blind. Unlike blind, though, leaned contains a stem that ends with $/ \mathrm{n} /$. Can children use the stem to overcome the phonologically based omission errors that might otherwise occur? Confirming the results of Treiman and Cassar (1996), we found that typical children in early elementary school do this to some extent. Specifically, the typically developing children were less likely to omit the first consonant of the final cluster in a morphologically complex word such as leaned than in a simple word such as blind. Importantly, we observed this same pattern in the older students with dyslexia. Although both the children with dyslexia and the younger typical children derived some benefit from root words in their spelling, neither group used morphological information as much as they could have. The students almost always included an $n$ when spelling a stem such as lean, but they sometimes omitted the $n$ when spelling a word such as leaned. Moreover, the children did not nec- essarily maintain other aspects of lean's spelling (such as its vowel letters) when they spelled leaned. These results suggest that the ability to use morphological information in spelling is fragile. Children make some use of higher level information to solve phonologically based segmentation problems, but they do not use this information fully.

In general, the spellings produced by the older children with dyslexia were similar to those produced by the younger children of the same spelling level. The older children with dyslexia appeared somewhat less likely to maintain the entire spelling of the stem when writing an inflected word, as in the studies of Carlisle (1987) and Hauerwas and Walker (2003), but the difference was not statistically reliable in the present experiment. The many similarities that we found between the spellings of older children with dyslexia and younger typical children support the results of several previous studies in which a spelling-level match design was used (Bourassa \& Treiman, 2003; Cassar, Treiman, Moats, Pollo, \& Kessler, 2005; Nelson, 1980). In those studies, older children with dyslexia performed very similarly to younger typical children in use of phonological information in spelling and in knowledge of legal and illegal spelling patterns. The present results suggest that these similarities extend to the morphological arena. We did not find any strong evidence to support the idea that students with dyslexia have more difficulty than spelling-level-matched younger students in using morphological information to aid their spelling.

\section{EXPERIMENT 2}

In English, morphological information can aid spelling in several ways. In Experiment 1, we examined a situation in which use of morphology could help children overcome a phonological segmentation problem that might otherwise lead to spelling errors. In Experiment 2, we turned to a case in which morphological information could help children deal with the one-to-many mappings between sounds and letters in the English spelling system. This specific case that we investigated involved the flaps that occur in North American English in such words as water and body. As was mentioned earlier, flaps are pronounced differently from typical $/ \mathrm{t} /$ and $/ \mathrm{d} /$ phonemes. The distinction between $/ \mathrm{t} /$ and $/ \mathrm{d} /$ that is found in most positions of words is said to be neutralized in this case. Because flaps are pronounced as voiced, they are more similar to /d/ than to $/ \mathrm{t} /$. Indeed, typical beginners often conceptualize flaps as /d/ and spell them as such (see, e.g., Ehri \& Wilce, 1986; Treiman et al., 1994). In the conventional English 


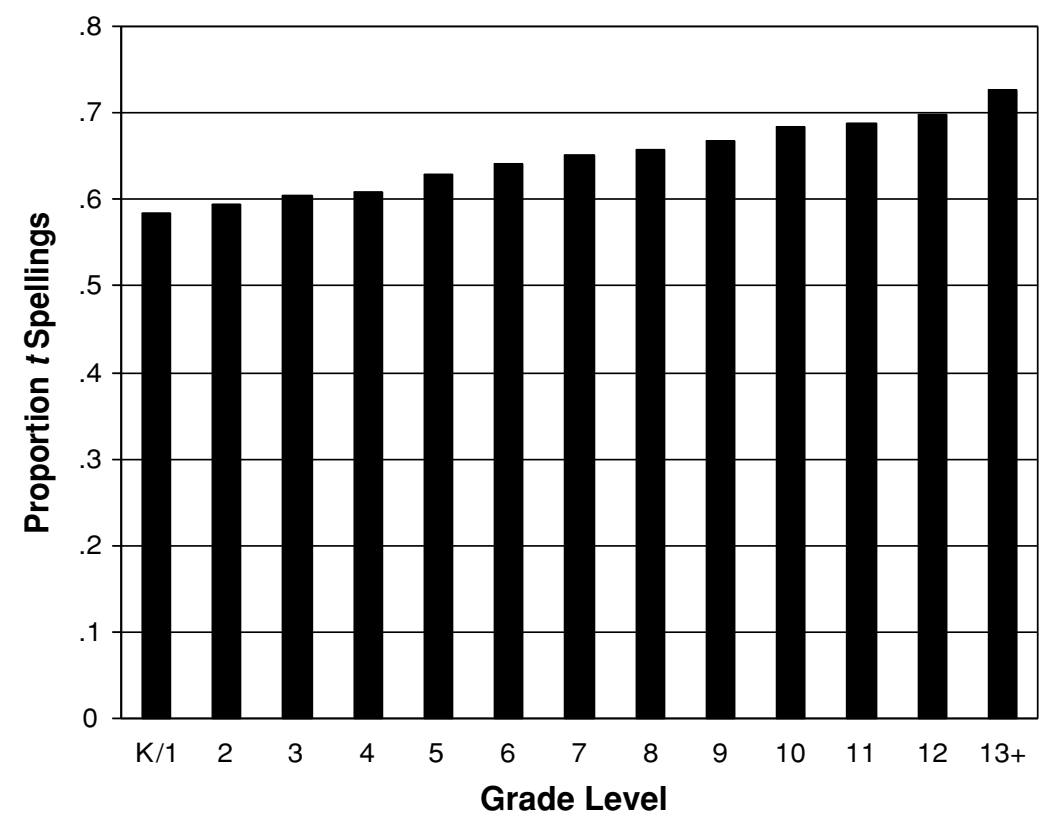

Figure 1. Proportions of spellings of flaps that contain $t$ in reading materials of different grade levels.

writing system, though, flaps are more often spelled with $t$ than with $d$. Figure 1 shows the proportion of printed words in reading materials designed for children of various grade levels in which flaps are symbolized with a single $t$ or a spelling containing $t$, such as $t t$. (In all of the words containing flaps that were analyzed, the conventional spellings of the flap contained at least one $d$ or at least one $t$, never both.) These figures were calculated by using all the words in the Carnegie Mellon Pronouncing Dictionary (Carnegie Mellon University, 1998) for which Zeno et al. (1995) show statistics broken down by grade level. The frequency of the words was taken into account by computing the natural log of the grade frequency data for each word before adding them together. As Figure 1 shows, flaps are spelled with $t$ over half the time in reading materials directed at children of all grade levels. The predominance of $t$ over $d$ is larger in higher level reading materials than in less advanced texts. These figures show that children who spelled flaps as voiced, in accord with how they sound, would make many errors.

Given that reliance on the sound properties of flaps would lead to many misspellings, can children use the morphological structure of a word containing a flap to infer the flap's spelling? For example, can children take into account the pronunciation of wait with / $\mathrm{t} /$ when spelling the flap of waiting? If so, children should produce more correct flap spellings in two-morpheme words, such as waiting, than in one-morpheme words, such as daughter. The typical young spellers tested by Treiman et al. (1994) showed such a difference. However, the children did not use their knowledge about stems to the maximum extent possible, in that they were less likely to use a $t$ when spelling waiting than when spelling wait. In Experiment 2, we asked whether children with dyslexia take advantage of morphology to help spell flaps. If so, do they use this information to the same extent as typical young children of the same spelling level?

\section{Method}

\section{Participants}

The participants were the same children as those who took part in Experiment 1.

\section{Stimuli}

The stimuli included 41 words, which were divided into two lists of 29 (List 1) and 12 (List 2) words each. The words are shown in Appendix B. List 1 included morphologically complex $t$-flap and $d$-flap words. These words, such as waiting and louder, were inflected or derived forms of stems with final /t/ or final /d/. List 1 also contained morphologically simple $t$-flap words. These words included a medial flap that was conventionally spelled with $t$, such as daughter, and they were not inflected or derived. Also included in List 1 were simple words with a medial flap that was conventionally spelled with $d$, such as spider. ${ }^{5}$ The remaining items in List 1 were control words. Half of the control words contained an unflapped medial $/ \mathrm{t} /$ that was spelled with $t$ (e.g., hotel), and the other half contained an unflapped medial /d/ that was spelled as $d$ (e.g., idea). List 2 comprised the stems of the morphologically complex words from List 1 (e.g., wait, loud). Within each list, the order of the words was randomized for presentation. The words were compared on two measures of word frequency (Carroll et al., 1971; Zeno et al., 1995) and word length (number of letters). Separate ANOVAs with word type (morphologically simple vs. morphologically complex vs. control vs. stem) and critical letter ( $t$ vs. $d$ ) as factors revealed only a main effect of word type $(p<.001)$ on the word length measure. The stems were shorter than the morphologically simple, morphologically complex, and control items, which did not differ in length.

\section{Procedure}

The procedure was identical to that in Experiment 1. All the children successfully repeated all the target words. 


\begin{abstract}
Scoring
Our primary interest was in how the children spelled the critical $t$ or $d$ in each word. For List 1 words with medial flaps that were spelled as $t$ and for List 1 control words with medial unflapped / $\mathrm{t} /$, the critical segment was scored as correct if the child's spelling contained at least one $t$ in any position except the first or the last. For $/ \mathrm{t} /$-stem words on List 2, the critical final/t/ was scored as correct if the last letter of the spelling was $t$, followed optionally by $e$. Words with $d$ were scored in an analogous fashion, and letter reversal errors (which were rare) were counted as correct. Errors were divided into two categories: those in which $t$ and $d$ were interchanged (e.g., "reting" for reading, "cidy" for city) and other types of errors (e.g. "bewy" for beauty, in which the flap was not represented). These other errors occurred less than $5 \%$ of the time, and the proportion of such errors did not differ significantly for the dyslexic and the nondyslexic children. The large majority of the children's errors on the critical segments, therefore, involved the substitution of $t$ for $d$ or $d$ for $t$.
\end{abstract}

\section{Results}

Table 4 shows the mean proportion of correct spellings of the critical segment for each type of word for the children with and without dyslexia. Separate analyses were conducted for morphologically complex and simple items with flaps, stems, and control items.

For the simple and complex items with flaps, an ANOVA with group (dyslexic vs. nondyslexic), morphology (simple vs. complex), and flap type ( $t$ vs. $d$ ) as factors revealed a main effect of morphology $\left[F_{1}(1,48)=68.56, p<.001\right.$; $\left.F_{2}(1,19)=17.16, p<.01\right]$. The children were more likely to spell the critical segment correctly when this segment occurred in a morphologically complex word, where the children were likely to be familiar with a stem that could aid their spelling, than when the segment occurred in a morphologically simple word. Also, morphology and flap type interacted $\left[F_{1}(1,48)=20.00, p<.001 ; F_{2}(1,19)=\right.$ $5.15, p<.05]$. This interaction arose because the advantage for complex words over simple words was larger for $d$-flap words than for $t$-flap words, although it was significant for both [for $d$-flap words, $t_{1}(49)=7.60, p<$ .001 , and $t_{2}(9)=4.56, p<.01$; for $t$-flap words, $t_{1}(49)=$ $3.29, p<.01$, and $\left.t_{2}(10)=1.33, p>.05\right]$. In addition, we observed an interaction between group and flap type $\left[F_{1}(1,48)=4.70, p<.05 ; F_{2}(1,19)=21.98, p<.001\right]$. The normally progressing children tended to spell flaps more accurately when the conventional spelling of the flap was $d$ as opposed to $t$. In contrast, the older children with dyslexia tended to perform more accurately on $t$ flaps than on $d$ flaps. This effect appeared to be especially strong for the simple words, but the interaction involving group, flap type, and morphology did not reach the .05 level either by participants or by items.

The results just presented show that the typically developing children, as a group, tended to spell flaps more accurately when the conventional spelling of the flap was $d$ than when it was $t$. The children with dyslexia, on the other hand, tended to perform better on $t$ flaps than on $d$ flaps. To explore this finding further, we examined the results for typically developing children as a function of their grade in school. The typical first graders performed significantly better on $d$ flaps than on $t$ flaps $(p<.05)$, the second graders performed equivalently on the two types of flaps, and the third graders did significantly better on the $t$ flaps $(p<.01)$. Thus, it was only the normally progressing children with the least amount of schooling who performed better on $d$ flaps than on $t$ flaps. The typical children who had more school experience showed the same pattern as the children with dyslexia: better performance on flaps that were conventionally spelled as $t$ than on flaps that were conventionally spelled as $d$.

Both the children with dyslexia and the typical children performed quite well on the stems and the control words. For the stems, a group (dyslexic vs. nondyslexic) $\times$ word type (critical segment /t/ vs. /d/) ANOVA revealed no significant effects. Nor were significant effects shown in the analysis of performance on control items.

If the children used their morphological knowledge to the maximum extent possible when spelling the morphologically complex words, they should have done as well on the flaps of words such as dirty and reading as on the final consonants of stems such as dirt and read. Given that the children almost always spelled the final sound of dirt with $t$, for example, they would have performed very well on the flap of dirty if they spelled it the same way. However, neither the children with dyslexia nor the typical children performed as well on the critical segments of the morphologically complex words as on the stems. Confirming this, a 2 (group: dyslexic vs. nondyslexic) $\times 2$ (word type: complex words vs. stem words) ANOVA on the proportion of correct spellings of the critical segments revealed a main effect of word type $\left[F_{1}(1,48)=42.72, p<.001\right.$; $\left.F_{2}(1,22)=51.28, p<.001\right]$. This ANOVA did not yield any other significant effects. The lack of a significant in-

Table 4

Mean Proportions of Correct Spellings of Critical Segment for Each Word Type in Experiment 2, With Standard Deviations

\begin{tabular}{|c|c|c|c|c|c|c|c|c|}
\hline \multirow[b]{2}{*}{ Group } & \multicolumn{2}{|c|}{$\begin{array}{l}\text { Morphologically } \\
\text { Simple }\end{array}$} & \multicolumn{2}{|c|}{$\begin{array}{c}\text { Morphologically } \\
\text { Complex }\end{array}$} & \multicolumn{2}{|c|}{ Stem } & \multicolumn{2}{|c|}{ Control } \\
\hline & $M$ & $S D$ & $M$ & $S D$ & $M$ & $S D$ & $M$ & $S D$ \\
\hline \multicolumn{9}{|c|}{$t$ Flap } \\
\hline Children with dyslexia & .75 & .27 & .81 & .23 & .99 & .05 & .96 & .15 \\
\hline Typical children & .67 & .36 & .78 & .31 & .99 & .05 & .99 & .07 \\
\hline \multicolumn{9}{|c|}{$d$ Flap } \\
\hline Children with dyslexia & .48 & .32 & .82 & .17 & .99 & .05 & .93 & .19 \\
\hline Typical children & .70 & .25 & .93 & .14 & .97 & .10 & .93 & .14 \\
\hline
\end{tabular}


teraction between group and word type shows that the difference in performance between stems and morphologically complex words was similar in size for the children with dyslexia and the typical children.

Further similarities between the two groups appeared when we examined how often children's spellings of the stem portions of the inflected and derived words agreed with their spellings of the stems when presented alone. This scoring used the same guidelines as those in the comparable analysis in Experiment 1 . For example, a child who spelled wait as "wat" and waiting as "wating" has maintained the spelling of the stem, whereas a child who spelled loud as "lude" and louder as "larder" did not spell the stem the same way. The proportion of cases in which the spelling of the stem was maintained in the twomorpheme word was .53 for the children with dyslexia and .54 for the typical children. This difference was not significant. These relatively low rates provide further evidence that neither group of children made full use of the stems when spelling the inflected and derived forms.

Although our main interest was in how the children spelled the flaps, we also scored the children's spellings of the entire words as correct or incorrect (see Table 5). A first analysis examined the proportions of correct responses to simple and complex items with flaps. An ANOVA with group (dyslexic vs. nondyslexic), morphology (simple vs. complex), and flap type ( $t$ vs. $d$ ) as factors revealed only a main effect of morphology $\left[F_{1}(1,48)=\right.$ $\left.46.13, p<.001 ; F_{2}(1,19)=4.45, p<.05\right]$. The children spelled morphologically complex words more accurately than morphologically simple words. Other analyses examined correct spellings of the stems and control words. For the stem items, a group (dyslexic vs. nondyslexic) $\times$ word type (critical segment /t/ vs. /d/) ANOVA revealed no significant effects. A parallel analysis for the control items yielded a main effect of word type $\left[F_{1}(1,48)=4.23, p<\right.$ $\left..05 ; F_{2}<1\right]$. The children spelled words with a medial/t/ more accurately than words with a medial /d/.

\section{Discussion}

Previous studies have shown that typical beginning spellers have trouble with flaps, where a given sound maps sometimes to $t$ and sometimes to $d$ (e.g., Read, 1975; Treiman, 1993; Treiman et al., 1994). We replicated this find- ing, showing that typically developing young children have more difficulty choosing between $t$ and $d$ when these letters correspond to flaps than when they correspond to nonflapped $/ \mathrm{t} / \mathrm{and} / \mathrm{d} /$. Confirming the preliminary findings of Bourassa and Treiman (2003), we also found that older children with dyslexia often misspell flaps. This outcome supports the idea that the same aspects of phonology that cause difficulties for typical beginning spellers also cause difficulties for older children with dyslexia (e.g., Bourassa \& Treiman, 2003; Cassar et al., 2005; Moats, 1983).

Children can solve the spelling problem with flaps, for certain words, if they consider the words' morphological structures. For example, children can correctly spell the flap of waiting if they relate it to wait. Normally developing children derive some such benefit from morphology from an early age (Treiman et al., 1994). For example, they perform better on the flap of waiting than on the flap of daughter because waiting has a stem, wait, in which the segment is pronounced as one of the more distinctive forms of $/ \mathrm{t} /$. We replicated this finding for the typically developing children in the present study. Moreover, we found that children with dyslexia also make some use of stems when selecting spellings for flaps in morphologically complex words. Neither the children with dyslexia nor the typical children used their knowledge of words' stems as much as they could have, in that neither group did as well on the medial segment of a word such as waiting as on the final segment of a word such as wait. In line with the findings of Experiment 1, though, the results suggest that both groups have some ability to use morphological relationships between words to aid their spelling.

Although the spellings produced by the older children with dyslexia and the typically developing younger children were similar in many ways, we observed a notable difference. The children with dyslexia tended to favor $t$ as a spelling for flaps, whereas the younger normal children as a group tended to favor $d$. Further analyses suggested that this pattern was due to the typical children with the least amount of school experience. The typical developing first graders were more likely to spell flaps as $d$ than as $t$. By third grade, though, $t$ spellings significantly outnumbered $d$ spellings, the same pattern as that shown by the group of children with dyslexia. Treiman et al. (1994) found a similar result in normally developing children: Those in

Table 5

Mean Proportions of Fully Correct Spellings of Each Word Type in Experiment 2, With Standard Deviations

\begin{tabular}{|c|c|c|c|c|c|c|c|c|}
\hline \multirow[b]{2}{*}{ Group } & \multicolumn{2}{|c|}{$\begin{array}{c}\text { Morphologically } \\
\text { Simple }\end{array}$} & \multicolumn{2}{|c|}{$\begin{array}{c}\text { Morphologically } \\
\text { Complex }\end{array}$} & \multicolumn{2}{|c|}{ Stem } & \multicolumn{2}{|c|}{ Control } \\
\hline & $M$ & $S D$ & $M$ & $S D$ & $M$ & $S D$ & $M$ & $S D$ \\
\hline \multicolumn{9}{|c|}{$t$ Flap } \\
\hline Children with dyslexia & .23 & .19 & .38 & .35 & .59 & .24 & .28 & .28 \\
\hline Typical children & .26 & .17 & .46 & .38 & .61 & .31 & .25 & .26 \\
\hline \multicolumn{9}{|c|}{$d$ Flap } \\
\hline Children with dyslexia & .20 & .23 & .41 & .26 & .57 & .27 & .16 & .20 \\
\hline Typical children & .33 & .23 & .51 & .29 & .57 & .28 & .24 & .26 \\
\hline
\end{tabular}


kindergarten through second grade tended to perform better on $d$ flaps than $t$ flaps, whereas fourth graders, when they erred on flaps, tended to show the opposite pattern. The present children with dyslexia do not, therefore, demonstrate a pattern of results that is unique to disabled spellers. Instead, it appears that children who have had more than a few years of experience with written English prefer to spell flaps with $t$ rather than with $d$. Our analysis of the English vocabulary suggests that this pattern reflects the fact that flaps are more often spelled with $t$ than with $d$ in English words. The imbalance becomes larger as children are exposed to more advanced reading materials, reinforcing the tendency to spell flaps with $t$.

\section{GENERAL DISCUSSION}

Dyslexia researchers have used spelling-level and reading-level match designs in the hope of discovering areas in which dyslexics perform especially poorly or especially well. If dyslexics show a pattern of skills that differs from that of typical young children, with notable weaknesses in some areas and relative strengths in others, this could provide insight into the causes of their reading and spelling problems and the ways in which these problems might be overcome. One hypothesis that has been explored in past research is that children with dyslexia have serious phonological problems for which they compensate, to some extent, by relatively good knowledge about legal and illegal letter patterns. According to this hypothesis, dyslexics should perform more poorly than normally progressing young children on tests of phonological skills but better on tests of graphotactic skills. Although some studies have shown such results (e.g., Siegel, Share, \& Geva, 1995), others have not (e.g., Cassar et al., 2005; Nelson, 1980).

Another hypothesis is that, as compared with younger normal children of the same spelling level, children with dyslexia are especially poor at taking advantage of the morphological aspects of English spelling. Although there is evidence that children with dyslexia have difficulty dealing with morphologically complex stimuli involving derived forms (Carlisle, 1987), analyses of how children deal with stimuli involving more transparent relations (e.g., inflected forms; Hauerwas \& Walker, 2003) have not provided conclusive results. The present experiments focused on the question of whether children with dyslexia can deal with situations in which a shorter word (e.g., tune, wait, need) that is transparently part of a longer one (e.g., tuned, waiting, needed) can be used to clarify the spelling of the longer word. The results showed that children with dyslexia have some ability to use morphology in this way. In Experiment 1, both the older children with dyslexia and the typical younger children were significantly less likely to omit the first consonant of a final cluster in morphologically complex words such as tuned than in morphologically simple words such as brand. In Experiment 2, the children in both groups produced significantly more correct spellings of flaps when they occurred in morphologically complex words, such as waiting and needed, than in morphologically simple words, such as daughter and spider. These effects were similar in size for the children with dyslexia and the typical younger spellers. Moreover, in both experiments, the children with dyslexia were not significantly less likely than comparison children to retain the entire spelling of a stem when spelling an inflected or derived word. There was a nonsignificant trend in this direction in Experiment 1, but very little difference in Experiment 2.

On the positive side, then, both the older children with dyslexia and the spelling-level-matched younger children made some use of morphology in spelling morphologically complex words. On the negative side, neither group used this information as much as they could have. For example, the dyslexic and control children in Experiment 1 were less likely to include an $n$ when spelling tuned than when spelling tune. Similarly, both groups of children in Experiment 2 produced some errors when spelling flaps in words such as waiting and needed, yet they almost always spelled the final sounds of their stems (i.e., wait and need) appropriately. In older spellers with dyslexia, as in normally progressing young spellers, use of morphology is fragile. This is true even for two-morpheme words with the most transparent structure possible: a free stem followed by an inflectional ending. As has been outlined by Schreuder and Baayen (1995), the processing of a morphologically complex word involves the mapping of the speech input onto its constituent morphological representations. Thus, for example, processing of the words tuned, waiting, and needed involves the coactivation of the representations for their respective stems and affixes (e.g., tune and -ed, wait and -ing, need and -ed). Subsequent integration of these activated representations can result in the correct spelling of these words. On the basis of the present findings, it appears that these processes are not fully operational in either normally developing or dyslexic children who are spelling, on average, at a Grade 2.6 level.

As was outlined earlier, the fact that our younger typically developing children failed to make full use of morphology is consistent with other investigations of this age group (Treiman \& Cassar, 1996; Treiman et al., 1994). The similar failure of our older dyslexic group points to a delay in their spelling development. This argument would be further supported if typically developing children comparable in age to our dyslexic group performed optimally on the morphologically complex items used here. Although the present experiments did not include an age-matched control group, other evidence suggests that the ability to deal effectively with these items is normally acquired by about 10 years of age. For example, Treiman and Cassar (1996, Experiment 1) reported that fourth graders (mean age of approximately 9 years, 11 months) represented the first phoneme of final consonant clusters with 99\% accuracy. Likewise, Treiman et al. (1994, Experiment 3 ) reported that children of this age provided the correct spelling of flaps (e.g., the $t$ in waiting and the $d$ in 
needed ) over $95 \%$ of the time. Thus, the present children with dyslexia did not achieve the level of performance that would be expected given their age.

To conclude, our results support the idea that the spellings produced by children with dyslexia are often quite similar to the spellings produced by young children who are learning to spell at a typical rate (see, e.g., Bourassa \& Treiman, 2003; Cassar et al., 2005; Moats, 1983; Nelson, 1980). The present findings, together with the previous results, indicate that dyslexic children experience many of the same kinds of difficulties in learning to spell and make errors on many of the same linguistic structures as typically developing children. That our groups did not make optimal use of morphological information in spelling suggests an avenue for instruction. Specifically, both groups of children could benefit from learning that morphemes are often spelled in a consistent fashion, even when affixes are added and even when pronunciations change. The children could also benefit from learning more about the morphological structure of spoken words. Arnbak and Elbro (2000) described a morphological awareness training program, focusing on the latter area, that yielded some benefits for spelling among Danish children with dyslexia. As these researchers suggest, training that included written materials as well could be even more effective. Learners of English need to understand that the spelling system reflects the morphological structure of words, as well as their phonological structure. This is an understanding that is not fully developed among children with reading and spelling problems or among normally progressing young children.

\section{REFERENCES}

ArnbaK, E., \& Elbro, C. (2000). The effects of morphological awareness training on the reading and spelling skills of young dyslexics. Scandinavian Journal of Educational Research, 44, 229-251.

Bourassa, D., \& Treiman, R. (2003). Spelling in children with dyslexia: Analyses from the Treiman-Bourassa Early Spelling Test. Scientific Studies of Reading, 7, 309-333.

BRUCK, M. (1988). The word recognition and spelling of dyslexic children. Reading Research Quarterly, 23, 51-69.

Bruck, M., \& Treiman, R. (1990). Phonological awareness and spelling in normal children and dyslexics: The case of initial consonant clusters. Journal of Experimental Child Psychology, 50, 156-178.

Caravolas, M., \& BRUCK, M. (1993). The effect of oral and written language input on children's phonological awareness: A cross-linguistic study. Journal of Experimental Child Psychology, 55, 1-30.

CARLISLE, J. F. (1987). The use of morphological knowledge in spelling derived forms by learning-disabled and normal students. Annals of Dyslexia, 27, 90-108.

Carlisle, J. F., \& Fleming, J. (2003). Lexical processing of morphologically complex words in the elementary years. Scientific Studies of Reading, 7, 239-253.

Carnegie Mellon University (1998). Carnegie Mellon pronouncing dictionary [Data file]. Retrieved May 28, 2003 from ftp://ftp.cs.cmu .edu/project/speech/dict/cmudict.0.6.

Carroll, J. B., Davies, P., \& Richman, B. (1971). Word frequency book. Boston: Houghton Mifflin.

Cassar, M., Treiman, R., Moats, L., Pollo, T. C., \& Kessler, B. (2005). How do the spellings of children with dyslexia compare with those of nondyslexic children? Reading \& Writing, 18, 29-47.
Chliounaki, K., \& Bryant, P. (2002). Construction and learning to spell. Cognitive Development, 17, 1489-1499.

EHRI, L. C., \& WILCE, L. S. (1986). The influence of spellings on speech: Are alveolar flaps /d/ or /t/? In D. B. Yaden \& S. Templeton (Eds.), Metalinguistic awareness and beginning literacy (pp. 101-114). Portsmouth, NH: Heinemann.

Elbro, C., \& ARnBAK, E. (1996). The role of morpheme recognition and morphological awareness in dyslexia. Annals of Dyslexia, 46, 209-240.

Fischer, F. W., Shankweiler, D., \& Liberman, I. Y. (1985). Spelling proficiency and sensitivity to word structure. Journal of Memory \& Language, 24, 423-441.

Goswami, U. (2003). Phonology, learning to read and dyslexia: A crosslinguistic analysis. In V. Csepe (Ed.), Dyslexia: Different brain, different behavior (pp. 1-40). New York: Kluwer/Plenum.

Hauerwas, L. B., \& Walker, J. (2003). Spelling of inflected verb morphology in children with spelling deficits. Learning Disabilities Research \& Practice, 15, 25-35.

International Phonetic Association (1999). Handbook of the International Phonetic Association: A guide to the use of the international phonetic alphabet. Cambridge: Cambridge University Press.

Kessler, B., \& Treiman, R. (2001). Relationship between sounds and letters in English monosyllables. Journal of Memory \& Language, 44, 592-617.

Kibel, M., \& Miles, T. R. (1994). Phonological errors in the spelling of taught dyslexic children. In C. Hulme \& M. Snowling (Eds.), Reading development and dyslexia (pp. 105-127). London: Whurr.

Liberman, I. Y., Shankweiler, D., Fischer, F. W., \& Carter, B. (1974). Explicit syllable and phoneme segmentation in the young child. Journal of Experimental Child Psychology, 18, 201-212.

MoAts, L. C. (1983). A comparison of the spelling errors of older dyslexic and second-grade normal children. Annals of Dyslexia, 33, 121140 .

NeLson, H. E. (1980). Analysis of spelling errors in normal and dyslexic children. In U. Frith (Ed.), Cognitive processes in spelling (pp. 475493). London: Academic Press.

Pacton, S., FAyol, M., \& Perruchet, P. (2002). The acquisition of untaught orthographic regularities in French. In L. Verhoeven, C. Elbro, \& P. Reitsma (Eds.), Precursors of functional literacy (pp. 121-137). Dordrecht: Kluwer.

Pennington, B. F., McCabe, L. L., Smith, S. D., Lefly, D. L., BooKman, M. O., Kimberling, W. J., \& LubS, H. A. (1986). Spelling errors in adults with a form of familial dyslexia. Child Development, 57, 1001-1013.

RaAjmakers, J. G., Schrijnemakers, J. M. C., \& Gremmen, F. (1999). How to deal with "the language-as-fixed-effect fallacy": Common misconceptions and alternative solutions. Journal of Memory \& Language, 41, 416-426.

READ, C. (1975). Children's categorization of speech sounds in English (NCTE Research Report No. 17). Urbana, IL: National Council of Teachers of English.

Schreuder, R., \& BAAYEN, R. H. (1995). Modeling morphological processing. In L. B. Feldman (Ed.), Morphological aspects of language processing (pp. 131-154). Hillsdale, NJ: Erlbaum.

SÉNÉCHAL, M. (2000). Morphological effects in children's spelling of French words. Canadian Journal of Experimental Psychology, 54, 76-85.

Siegel, L. S., Share, D., \& Geva, E. (1995). Evidence for superior orthographic skills in dyslexics. Psychological Science, 6, 250-254.

Sterling, C. M. (1983). Spelling errors in context. British Journal of Psychology, 74, 353-364.

Treiman, R. (1991). Children's spelling errors on syllable-initial consonant clusters. Journal of Educational Psychology, 83, 346-360.

Treiman, R. (1993). Beginning to spell: A study of first-grade children. New York: Oxford University Press.

Treiman, R., \& CASSAR, M. (1996). Effects of morphology on children's spelling of final consonant clusters. Journal of Experimental Child Psychology, 63, 141-170.

Treiman, R., Cassar, M., \& Zukowski, A. (1994). What types of linguistic information do children use in spelling? The case of flaps. Child Development, 65, 1310-1329. 
Treiman, R., \& Zukowski, A. (1991). Levels of phonological awareness. In S. A. Brady \& D. P. Shankweiler (Eds.), Phonological processes in literacy: A tribute to Isabelle Y. Liberman (pp. 67-83). Hillsdale, NJ: Erlbaum.

Treiman, R., Zukowski, A., \& Richmond-Welty, E. D. (1995). What happened to the " $n$ " of sink? Children's spellings of final consonant clusters. Cognition, 55, 1-38.

WECHSLER, D. (1991). Manual for the Wechsler Intelligence Scale for Children (3rd ed.). San Antonio, TX: Psychological Corporation.

Wilkinson, G. (1993). The Wide Range Achievement Test (3rd ed.). Wilmington, DE: Wide Range, Inc.

Zeno, S. M., Ivenz, S. H., Millard, R. T., \& Duvvuri, R. (1995). Educator's word frequency guide. Brewster, NY: Touchstone Applied Science Associates.

\section{NOTES}

1. Phonemes are represented using the alphabet of the International Phonetic Association (1999).

2. Each of the WRAT3 (Wilkinson, 1993) spelling and reading subtests has two alternate forms. Wilkinson recommends the use of both forms for a more comprehensive test of spelling and reading skills. Each child's spelling score is based on his or her combined score across the two spelling forms, and likewise for the reading score. The grade levels and percentiles we report are based on the combined age norms listed in the WRAT3 Manual.

3. The two groups showed very similar distributions in terms of spelling-grade-level performance. For the dyslexic group, the numbers of children spelling at the Grade 1,2, and 3 levels were 8 (mean grade level $=1.8), 7$ (mean grade level $=2.4)$, and 10 (mean grade level $=$ 3.4 ), respectively. For the control group, the numbers were 8 (mean grade level $=1.7), 8($ mean grade level $=2.6)$, and 9 (mean grade level $=$ $3.5)$, respectively.

4. Raaijmakers, Schrijnemakers, and Gremmen (1999) argued that when, as here, experiments involve sets of matched items (i.e., the items are not randomly chosen from the population of all possible items), the assumption of random sampling for the items ANOVA is violated. Raaijmakers et al. argued that, in such cases, item analyses become insensitive and prone to Type 2 error and that participant analyses are sufficient for rejection of the null hypothesis. Thus, for the present experiments, we will focus on the results and interpretation of the by-participants $\left(F_{1}\right)$ analyses, although we will include the parallel findings of the by-items analyses $\left(F_{2}\right)$.

5. One other word was originally intended for this category, but it was not always pronounced with a flap and so was not included in the analyses.

\section{APPENDIX A \\ Stimuli in Experiment 1}

Words with final clusters (followed by the spellings that were considered reasonable for each of the final phonemes):

Morphologically complex: bars $(r, s / z)$, tuned $(n, d / t)$, leaned $(n, d / t)$, loaned $(n, d / t)$, earned $(n, d / t)$, rained $(n, d / t)$, shared $(r, d / t)$, laced $(c / s, d / t)$, faced $(c / s, d / t)$, raced $(c / s, d / t)$, creeps $(p, s / z)$, kicked $(c / k, d / t)$, baked $(c / k, d / t)$, raked $(c / k, d / t)$, puffed $(f / p h, d / t)$

Morphologically simple: Mars $(r, s / z)$, brand $(n, d / t)$, blond $(n, d / t)$, mound $(n, d / t)$, hound $(n, d / t)$, blind $(n$, $d / t)$, beard $(r, d / t)$, arrest $(c / s, d / t)$, feast $(c / s, d / t)$, boast $(c / s, d / t)$, collapse $(p, s / z)$, collect $(c / k, d / t)$, elect $(c / k$, $d / t)$, connect $(c / k, d / t)$, drift $(f / p h, d / t)$

Words without final clusters (followed by the spellings that were considered reasonable for the final phoneme):

bar $(r)$, tune $(n)$, lean $(n)$, loan $(n)$, earn $(n)$, rain $(n)$, share $(r)$, lace $(c / s)$, face $(c / s)$, race $(c / s)$, creep $(p)$, kick $(c / k)$, bake $(c / k)$, rake $(c / k), p u f f(f / p h)$

\section{APPENDIX B \\ Stimuli in Experiment 2}

$t$ flap words, morphologically complex:

fighting, later, waiting, shouted, shortest, eater

$d$ flap words, morphologically complex:

reading, louder, sliding, bloody, hiding, needed

$t$ flap words, morphologically simple:

photo, party, city, beauty, daughter, motor

$d$ flap words, morphologically simple:

modern, sturdy, shadow, spider, body

$t$ flap words, stems:

eat, fight, late, shout, wait, short

$d$ flap words, stems:

read, blood, loud, hide, need, slide

$t$ control words:

contain, hotel, return

$d$ control words:

sardines, idea, adult 